\title{
Screening for trisomy 21 based on maternal age, nuchal translucency measurement, first trimester biochemistry and quantitative and qualitative assessment of the flow in the DV - the assessment of efficacy
}

\author{
Bartosz Czuba' ${ }^{1}$, Dariusz Zarotyński ${ }^{2}$, Mariusz Dubiel ${ }^{3}$, Dariusz Borowski ${ }^{4}$, Piotr Węgrzyn ${ }^{5}$, \\ Wojciech Cnota ${ }^{1}$, Małgorzata Reska-Nycz ${ }^{1}$, Marek Mączka ${ }^{6}$, Mirosław Wielgoś ${ }^{4}$, \\ Krzysztof Sodowski ${ }^{1}$, Dawid Serafin ${ }^{1}$, Anna Kubaty ${ }^{7}$, Grzegorz H. Bręborowicz ${ }^{8}$ \\ ${ }^{1}$ Department of Obstetrics and Gynecology in Ruda Slaska, Medical University of Silesia, Poland \\ ${ }^{2}$ The Rafal Czerwiakowski Gynecological-Obstetrical Hospital, Krakow, Poland \\ ${ }^{3}$ Department of Maternal-Fetal Medicine and Gynecology, Chair of Obstetrics, Bydgoszcz, Poland \\ ${ }^{4} 1^{\text {st }}$ Department of Obstetrics and Gynaecology, Medical University of Warsaw, Poland \\ ${ }^{5}$ Department of Obstetrics and Perinatology, Medical University of Warsaw, Poland \\ ${ }^{6}$ Gynecological-Obstetrical Hospital in Opole, Poland \\ ${ }^{7}$ Department of Obstetrics, Gynecology and Oncology, The Gabiel Narutowicz Hospital, Krakow, Poland \\ ${ }^{8}$ Department of the Perinatology and Gynecology, Poznan University of Medical Sciences, Poland
}

\begin{abstract}
Objectives: The aim of the study was to compare effects of addition of two methods of ductus venosus (DV) flow assessment: qualitative - the assessment of shape of the A-wave (positive or negative), and quantitative - based on the pulsatility index for veins (DVPI) to the basic screening for trisomy 21 at 11 to $13+6$ weeks of pregnancy.

Material and methods: The ultrasound examination was performed in 8230 fetuses in singleton pregnancies at $11-$ $-13+6 \mathrm{wks}$, as a part of a routine screening for chromosomal defects. In DV A-wave was assessed and DVPI was calculated. After the scan blood sample was taken for first trimester biochemistry (BC). Risk for chromosomal defects was calculated and high-risk patients were offered an invasive test for karyotyping.

Results: Basic screening with following combination of markers: MA, NT and BC provided lowest detection rate (DR) $87.50 \%$ for $F P R=6.94 \%$. After adding qualitative DV A-wave assessment DR increased to $88.75 \%$ for FPR $=5.65 \%$. The best $\mathrm{DR}=93.75 \%$ for $\mathrm{FPR}=5.55 \%$ was achieved when quantitative DVPI was added. The application of the Receiver Operating Curves curve confirmed validity of the addition of DV flow assessment to the screening model. The highest diagnostic power of the test was achieved when DVPI was added, with the ROC AUC of 0.974 .

Conclusions: The assessment of DV flow performed at 11-13+6 weeks increases DR for trisomy 21 and reduces FPR. The screening model based on the quantitative DV flow analysis (DVPI) gives better results compared to the qualitative flow assessment.
\end{abstract}

Key words: screening for chromosomal defects, 11 to $13+6$ weeks scan, trisomy 21 , ductus venosus 


\section{INTRODUCTION}

The ultrasound examination performed at 11 to $13+6$ weeks of pregnancy allows for the assessment of the fetal structure, but also identification of fetuses at increased risk of chromosomal defects [1-3]. Nuchal translucency (NT) is considered to be the strongest marker of chromosomal defects, but in order to increase sensitivity and specificity some additional ultrasound markers are also assessed, including the nasal bone (NB), flow through the tricuspid valve (Tricuspid Regurgitation, TR), and flow through the ductus venosus (DV) [3,4]. The use of the last marker is increasing in screening for chromosomal defects and cardiac defects $[3,5,6]$. There are two methods of the DV assessment: qualitative - the assessment of the shape of the A-wave (the atrial component of the waveform), and quantitative - DVPI based on the pulsatility index for veins (PIV) $[5,7,8]$ The screening algorithm for trisomy 21 (Down's Syndrome) involving maternal age (MA), NT, and first trimester biochemistry $(\mathrm{BC})$ - serum free beta subunit of chorionic gonadotropin (free $\beta$-hCG), and pregnancyassociated plasma protein A (PAPP-A) levels expressed in MoMs - shows detection rate (DR) of $91 \%$ and $3 \%$ false positive rate (FPR). According to previous studies, adding the assessment of the DV increases DR of the test to $96 \%$ whereas FPR remains at the level of $3 \%[5,8]$.

\section{OBJECTIVES}

The aim of the study was to evaluate and compare qualitative and quantitative methods of assessment of blood flow in the DV as additional parameters in screening for trisomy 21 at 11 to $13+6$ wks.

\section{MATERIAL AND METHODS}

The ultrasound examinations (Voluson Expert VE 730 and Voluson Expert E8, General Electric) was performed in 8230 singleton pregnancies by doctors certified by the Fetal Medicine Foundation (FMF), as a part of a routine screening for chromosomal defects at 11 to $13+6$ wks, between 2010 and 2014. Given the methodology of this study (retrospective, anonymized, non-interventional), as per the local rules, there was no need for review by a research ethics board.

The following were assessed: crown rump length (CRL), fetal heart rate (FHR), NT, and DV flow analysed using two different methods. The first method involved the assessment of presence/absence of the A-wave, and the second was based on the measurement of DVPI according to FMF rules. The fetal anatomy was assessed to exclude structural abnormalities (according to International Society of Ultrasound in Obstetrics and Gynecology guidelines).

Maternal blood samples were collected from all patients for the assessment of the serum level of the free $\beta$-hCG and PAPP-A (FMF-certified: Delfia Express, Perkin-Elmer), subsequently expressed in MoMs for risk calculation (first trimester biochemistry - BC). The risk for trisomy 21 was calculated using the FMF-certified software (Astraia, Astraia Software Gmbh).

We analysed three models in screening for trisomy 21 - first: NT + BC, second: NT + BC + DV A-wave, and third: NT + BC+ DVPI. The cut off for invasive testing was 1:300 in all models. In high-risk patients, an invasive procedure (amniocentesis) was performed for fetal karyotyping. Where the karyotype result was not available, healthy neonates were assessed phenotypically (follow-up).

\section{The statistical analysis}

The XLSTAT software for Microsoft Excel was used for the statistical analysis. Data were assessed for normality of the distribution using Shapiro-Wilk test, and the U Mann-Whitney test was used for non-normal distribution. Qualitative parameters were analysed using the $\mathrm{Chi}^{2}$ test. The ROC curves were used to determine the diagnostic threshold values. Sensitivity and specificity were calculated for each threshold value. In all tests the statistical significance was assessed by $p$ value, which was considered significant if lower than 0.05 .

\section{RESULTS}

7554 fetuses were included in the final analysis. Remaining 676 cases with other chromosomal defects, or normal karyotype and congenital abnormalities, or because of being lost to follow-up were excluded from the study. The gestational age was determined based on the CRL measurement. Among 7554 patients, trisomy 21 was found in 80 cases $(1.06 \%)$. The remaining 7474 fetuses presented normal phenotype (98.94\%). The characteristics of the study population are shown in Table 1.

An abnormal DV A-wave was found in 258 (3.45\%) of fetuses with a normal karyotype and in 38 (47.5\%) with trisomy 21 ( $p<0.0001)$.

The highest DR (93.75\%) was achieved when DVPI calculation was introduced to the model. When determination of presence/absence of DV A-wave was added, DR was significantly lower (88.75\%). The lowest DR (87.5\%) was found in the basic model without DV flow assessment.

In NT + BC + DVPI model for the 1:300 and 1:200 cut-offs for high risk for trisomy 21 the same DR was achieved (93.75\%), but for the 1:200 cut-off FPR was lower (reduction from $5.55 \%$ to $3.72 \%)$. Interestingly in NT + BC + DV A-wave model for the 1:300 and 1:200 cut-offs, DR was also the same $(88.75 \%)$ and for the 1:200 cut-off FPR was lower (reduction from $5.65 \%$ to $3.88 \%$ ). For cut-offs of 1:100 and 1:50 DRs were markedly worse (Tables 2-4).

The introduction of the DVPI assessment allowed creating the best model with DR of $93.75 \%$ and FPR 5.55\%. 
Table 1. Characteristics of the study population

\begin{tabular}{|c|c|c|c|c|c|c|c|c|c|c|c|}
\hline \multirow{2}{*}{ Variable } & \multicolumn{2}{|c|}{ Mean } & \multicolumn{2}{|c|}{ SD } & \multicolumn{2}{|c|}{ Minimum } & \multicolumn{2}{|c|}{ Median } & \multicolumn{2}{|c|}{ Maximum } & \multirow{2}{*}{ p } \\
\hline & $\mathbf{N}$ & T21 & $\mathbf{N}$ & T21 & $\mathbf{N}$ & T21 & $\mathbf{N}$ & T21 & $\mathbf{N}$ & T21 & \\
\hline Maternal age (years) & 32.58 & 29.38 & 5.17 & 4.95 & 14.00 & 22.00 & 34.00 & 28.00 & 46.00 & 43.00 & $<0.0001$ \\
\hline CRL [mm] & 62.82 & 63.83 & 8.37 & 10.82 & 45.00 & 45.00 & 62.70 & 64.50 & 84.00 & 84.00 & $<0.0001$ \\
\hline NT [mm] & 1.75 & 4.87 & 0.48 & 1.82 & 0.80 & 1.80 & 1.70 & 4.85 & 10.00 & 8.02 & $<0.0001$ \\
\hline FHR (bpm) & 160.47 & 160.91 & 6.01 & 8.48 & 122.00 & 145.00 & 161.00 & 162.00 & 206.00 & 181.00 & $<0.0001$ \\
\hline$\beta$-hCG (MoM) & 1.34 & 1.76 & 0.92 & 0.89 & 0.09 & 0.20 & 1.07 & 1.75 & 7.70 & 4.37 & $<0.0001$ \\
\hline PAPP-A (MoM) & 1.07 & 0.88 & 0.62 & 0.76 & 0.12 & 0.16 & 0.97 & 0.69 & 9.74 & 4.49 & $<0.0001$ \\
\hline DV-PI & 1.053 & 1.764 & 0.31 & 0.68 & 0.47 & 0.8 & 1.00 & 2.0 & 3.1 & 2.9 & $<0.0001$ \\
\hline
\end{tabular}

$\mathrm{CRL}$ — crown rump length; NT — nuchal translucency; FHR — fetal heart rate; $\beta$-hCG — free $\beta$ subunit of chorionic gonadotropin; PAPP-A — pregnancy-associated plasma protein A; MoM - median; DV-PI — pulsatility index for the ductus venosus

Table 2. The analysis of DR and FPR in NT + BC model

\begin{tabular}{|l|c|c|c|c|}
\hline Risk & $1: 300$ & $1: 200$ & $1: 100$ & $1: 50$ \\
\hline DR (\%) & 87.50 & 86.25 & 83.75 & 81.25 \\
\hline FPR (\%) & 6.94 & 5.3 & 2.6 & 1.30 \\
\hline
\end{tabular}

DR - sensitivity; FPR - number of false positive results

\begin{tabular}{|l|c|c|c|c|}
\hline \multicolumn{4}{|c|}{ Table 3. The analysis of DR and FPR in NT + BC + DV A-wave model } \\
\hline Risk & $\mathbf{1 : 3 0 0}$ & $\mathbf{1 : 2 0 0}$ & $\mathbf{1 : 1 0 0}$ & $\mathbf{1 : 5 0}$ \\
\hline DR (\%) & 88.75 & 88.75 & 85.00 & 57.50 \\
\hline FPR (\%) & 5.65 & 3.88 & 2.44 & 1.77 \\
\hline
\end{tabular}

DR - sensitivity; FPR - number of false positive results

\section{Table 4. The analysis of DR and FPR in NT + BC + DVPI model}

\begin{tabular}{|l|c|c|c|c|}
\hline Risk & $\mathbf{1 : 3 0 0}$ & $\mathbf{1 : 2 0 0}$ & $\mathbf{1 : 1 0 0}$ & $\mathbf{1 : 5 0}$ \\
\hline DR (\%) & 93.75 & 93.75 & 86.25 & 61.25 \\
\hline FPR (\%) & 5.55 & 3.72 & 2.37 & 1.8 \\
\hline
\end{tabular}

DR - sensitivity; FPR - number of false positive results

Increasing the risk cut-off to $1: 200$ reduces FPR to $3.72 \%$ without changing DR (Table 4).

The application of the ROC curve for the analysis confirmed validity of addition of the qualitative and quantitative DV markers. The diagnostic power of the test was highest for DVPI, with the ROC AUC value of 0.974 (Figures 1-3). Table 5 presents results of comparison of the ROC curves depending on the additional DV marker used.

\section{DISCUSSION}

The main goal of non-invasive prenatal screening for Down's syndrome is selection of high-risk patients who should be offered an invasive testing. The main challenge in screening is achieving the highest possible DR and lowest FPR $[3,9]$. The addition of DV flow analysis, after obtaining trisomy 21 risk

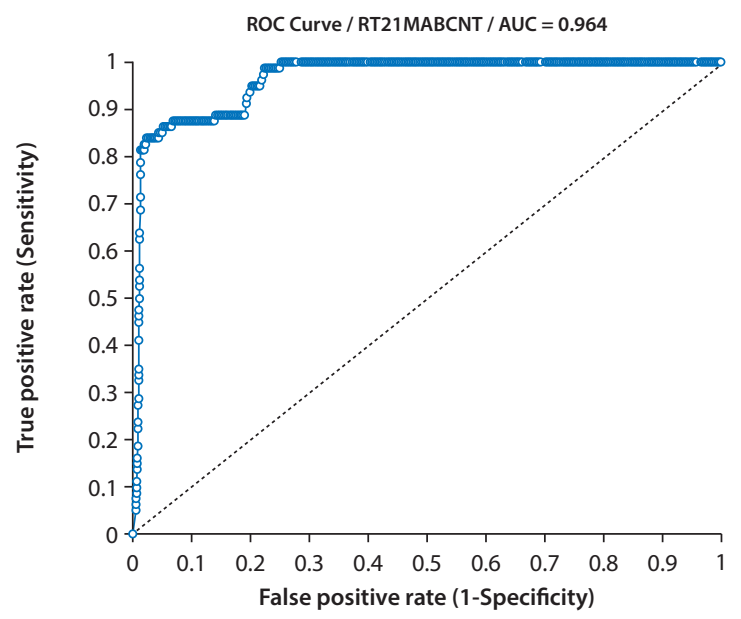

Figure 1. The ROC curve for NT + BC model

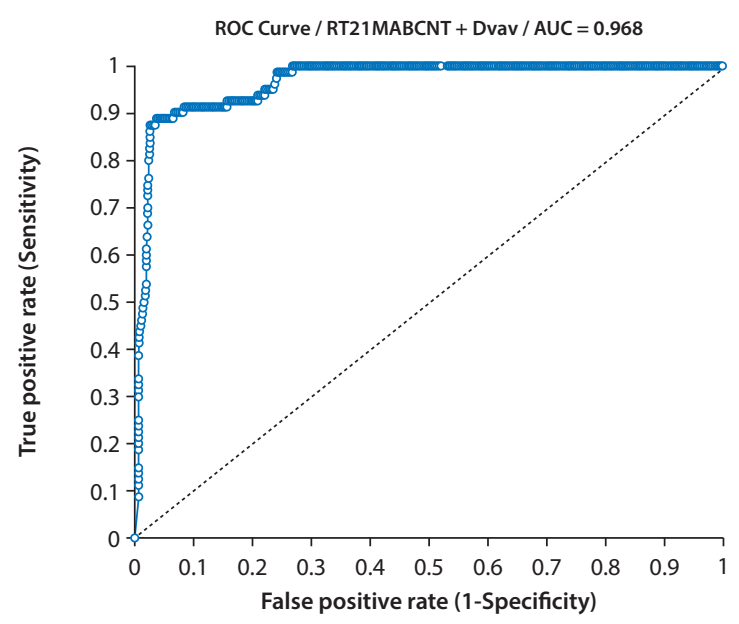

Figure 2. The ROC curve for NT + BC + DV A-wave model

calculated based on NT + BC, allows for more precise separation of the group with a high trisomy 21 risk, as compared to the method based on NT + BC only $[3,5]$. Abnormal DV in trisomy 21 is assumed to be indicative of impaired diastolic 
Table 5. Diagnostic values of assessed parameters based in the area under the curve for ROC

\begin{tabular}{|l|c|c|c|}
\hline Risk calculation model & Area under the curve (AUC) & Standard error & Confidence level (95\%) \\
\hline NT + BC & 0.964 & 0.007 & $0.950-0.979$ \\
\hline NT + BC + DV A-wave & 0.968 & 0.007 & $0.954-0.982$ \\
\hline NT + BC + DVPI & 0.974 & 0.006 & $0.962-0.987$ \\
\hline
\end{tabular}

DV — ductus venosus; DVPI — ductus venosus pulsatility index

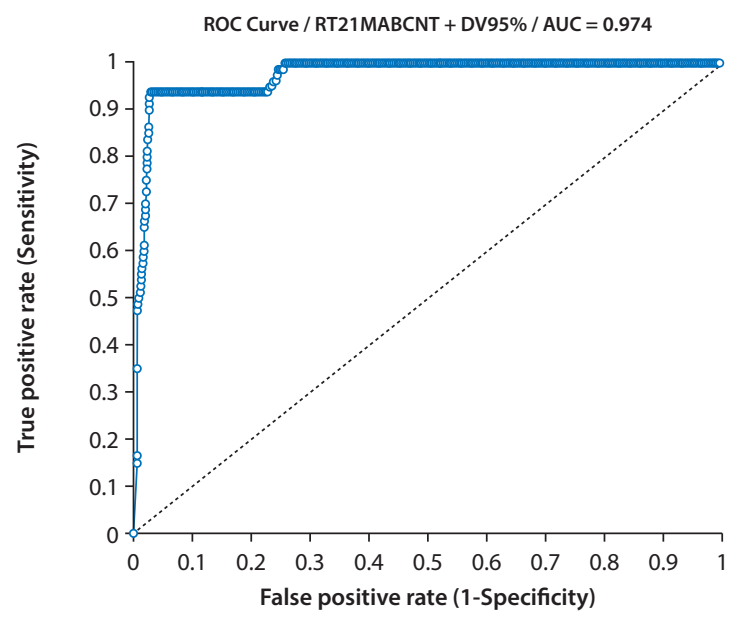

Figure 3. The ROC curve for NT + BC + DVPI model

function (ventricular filling) due to volume overload [11]. Interestingly, abnormal DV Doppler test in euploid fetuses in the first trimester is associated with poor obstetric outcomes, including higher rate of placental abruption, preterm delivery, lower birth weight and lower Apgar scores [12].

In trisomy 21 screening based on NT + BC, DR is approximately $90 \%$, with FPR of about 3-5\% [3, 10]. In our data for NT + BC, DR is $87 \%$, and FPR $-6.94 \%$, for the cut-off risk at 1:300. And the qualitative assessment of flow (DV A-wave) increases DR to $88.75 \%$, with FPR of $5.65 \%$. Those are slightly better results compared to the trisomy 21 risk assessment based on NT + BC only. In case of the analysis of presence of the DV A wave, Nicolaides reports DR of $91.93 \%$, with FPR of $2.5 \%[13,14]$.

Results of this study demonstrate that it is possible to achieve DR of $93.75 \%$, with simultaneous reduction of FPR to $5.55 \%$, with DVPI analysis. Further reduction of FPR to $3.75 \%$ can be achieved increasing high-risk cut-off form 1:300 to 1:200 without change in DR. Mainz et al. noted DR at the level of $95 \%$, with FPR of $2.9 \%$. In our study, the abnormal DV A-wave was observed in 258 (3.45\%) of fetuses with a normal karyotype and in $38(47.5 \%)$ with trisomy 21 ( $p<0.0001)$. Literature data indicate a broad scope of presence of the abnormal A-wave in DV 7.7\% - 38.3\% in trisomy 21 cases $[15,16]$. A similarly broad scope of presence of the reversed DV A-wave was observed in normal fetuses (2.0-13.0\%).
Maiz and Nicolaides reported that an abnormal flow in the DV was observed in $69.1 \%$ of trisomy 21 fetuses, and in $3.7 \%$ of chromosomally normal fetuses $[5,17]$. First reports of the use of the DV flow assessment in trisomy 21 screening have been published in 1990's [16].

Undoubtedly, the addition of the qualitative assessment of the DV flow (DV A-wave) to the screening of trisomy 21 improves its efficacy [10]. DVPI assessment not only increases DR and decreases FPR in trisomy 21 screening, but also improves detection of congenital heart defects $[18,19]$. Our results demonstrate that adding DVPI measurement increases DR from $87.5 \%$ to $93.75 \%$, with decrease of FPR from $6.94 \%$ to $5.55 \%$. Using the double-step screening model for trisomy 21 with DVPI analysis, Maiz et al. achieved the DR of 93.5\% and FPR of $1.63 \%$ [5].

Wagner et al. in a retrospective study compared DV assessment in screening for trisomy 21 flow either as dichotomous classification of the a-wave, as measurement of the DV PIV, or both. The DV a-wave was reversed in $2.3 \%$ and $66.1 \%$ in the euploid and trisomy 21 fetuses, respectively. The DV PIV measurements were above the $95^{\text {th }}$ percentile in $8.3 \%$ and $77.2 \%$ the euploid cases and trisomy 21 , respectively. They found that for a FPR of 3\%, the DR for trisomy 21 based on maternal age, fetal NT, and DV flow was about $87 \%$ irrespective of whether DV is examined as a continuous or dichotomous variable [20]. In a study of the performance of the first trimester ultrasound screening for trisomy 21 with additional ultrasound parameters: nasal bone (NB), tricuspid flow (TF) and ductus venosus (DV) the authors found that DR is substantially higher if all three additional markers rather than just one are assessed [21]. The later clearly shows that quality ultrasound scan performed in specialized centers performs better in screening that basic ultrasound.

Our study shows that introducing the quantitative analysis of the DV flow (DVPI) improves screening for trisomy 21 at 11-13+6 wks based on assessment of nuchal translucency and first trimester biochemistry more than adding just the qualitative assessment of the DV flow (DV A-wave).

\section{CONCLUSIONS}

The assessment of the DV flow performed at $11-$ $-13+6$ wks increases detection rate and reduces false positive rate in screening for trisomy 21 . 
The screening model based on the quantitative DV flow (DV PI) analysis gives better results as compared to the qualitative flow assessment (DV A-wave).

\section{REFERENCES}

1. Cnota W, Borowski D, Wloch A, et al. Pomiar kata twarzowo-szczekowego u płodów pomiędzy $11+0$ a 13+6 tygodniem ciąży. Zastosowanie w diagnostyce prenatalnej trisomii 21. Ginekol Pol. 2013; 84(7):624-629.

2. Czuba B, Cnota W, Wloch A, et al. Frontomaxillary facial angle measurement in screening for trisomy 18 at $11+0$ to $13+6$ weeks of pregnancy: a double-centre study. Biomed Res Int. 2013; 2013: 168302, doi: 10.1155/2013/168302, indexed in Pubmed: 24195065.

3. Wright D, Syngelaki A, Bradbury l, et al. First-trimester screening for trisomies 21, 18 and 13 by ultrasound and biochemical testing. Fetal Diagn Ther. 2014; 35(2): 118-126, doi: 10.1159/000357430, indexed in Pubmed: 24356462.

4. Nicolaides $\mathrm{KH}$. A model for a new pyramid of prenatal care based on the 11 to 13 weeks' assessment. Prenat Diagn. 2011; 31(1): 3-6, doi: 10.1002/pd.2685, indexed in Pubmed: 21210474.

5. Maiz N, Wright $D$, Ferreira AF, et al. A mixture model of ductus venosus pulsatility index in screening for aneuploidies at 11-13 weeks' gestation. Fetal Diagn Ther. 2012; 31(4):221-229, doi: 10.1159/000337322, indexed in Pubmed: 22614037.

6. Chelemen T, Syngelaki A, Maiz N, et al. Contribution of ductus venosus Doppler in first-trimester screening for major cardiac defects. Fetal Diagn Ther. 2011; 29(2): 127-134, doi: 10.1159/000322138, indexed in Pubmed: 21160164.

7. Maiz N, Valencia C, Emmanuel EE, et al. Screening for adverse pregnancy outcome by ductus venosus Doppler at $11-13+6$ weeks of gestation. Obstet Gynecol. 2008; 112(3): 598-605, doi: 10.1097/AOG.0b013e3181834608, indexed in Pubmed: 18757658.

8. Maiz N, Valencia C, Kagan KO, et al. Ductus venosus Doppler in screening for trisomies 21,18 and 13 and Turner syndrome at 11-13 weeks of gestation. Ultrasound Obstet Gynecol. 2009; 33(5): 512-517, doi: 10.1002/uog.6330, indexed in Pubmed: 19338027.

9. Kagan KO, Wright $D$, Nicolaides KH. First-trimester contingent screening for trisomies 21, 18 and 13 by fetal nuchal translucency and ductus venosus flow and maternal blood cell-free DNA testing. Ultrasound Obstet Gynecol. 2015; 45(1): 42-47, doi: 10.1002/uog.14691, indexed in Pubmed: 25307357.

10. Nicolaides K. Screening for fetal aneuploidies at 11 to 13 weeks. Prenatal Diagnosis. 2011; 31(1): 7-15, doi: 10.1002/pd.2637.

11. Mula R, Grande M, Bennasar M, et al. Further insights into diastolic dysfunction in first-trimester trisomy-21 fetuses. Ultrasound Obstet
Gynecol. 2015; 45(2): 205-210, doi: 10.1002/uog.13380, indexed in Pubmed: 24706444.

12. Seckin KD, Karslı MF, Baser E, et al. Obstetric outcomes in pregnancies with normal nuchal translucency and abnormal ductus venosus Doppler in the first trimester ultrasonography. J Obstet Gynaecol. 2016; 36(4): 440-443, doi: 10.3109/01443615.2015.1060210, indexed in Pubmed: 26457755.

13. Kagan KO, Wright $D$, Spencer $K$, et al. First-trimester screening for trisomy 21 by free beta-human chorionic gonadotropin and pregnancy-associated plasma protein-A: impact of maternal and pregnancy characteristics. Ultrasound Obstet Gynecol. 2008; 31(5): 493-502, doi: 10.1002/uog.5332, indexed in Pubmed: 18432600.

14. Kagan KO, Staboulidou I, Cruz J, et al. Two-stage first-trimester screening for trisomy 21 by ultrasound assessment and biochemical testing. UItrasound Obstet Gynecol. 2010; 36(5): 542-547, doi: 10.1002/uog.7663, indexed in Pubmed: 20503223.

15. Prefumo F, Sethna F, Sairam S, et al. First-trimester ductus venosus, nasal bones, and Down syndrome in a high-risk population. Obstet Gynecol. 2005; 105(6): 1348-1354, doi: 10.1097/01.AOG.0000161368.77506.ab, indexed in Pubmed: 15932828.

16. Matias A, Huggon I, Areias JC, et al. Cardiac defects in chromosomally normal fetuses with abnormal ductus venosus blood flow at 10-14 weeks. Ultrasound Obstet Gynecol. 1999; 14(5): 307-310, doi: 10.1046/j.1469-0705.1999.14050307.x, indexed in Pubmed: 10623988.

17. Maiz N, Nicolaides KH. Ductus venosus in the first trimester: contribution to screening of chromosomal, cardiac defects and monochorionic twin complications. Fetal Diagn Ther. 2010; 28(2): 65-71, doi: 10.1159/000314036, indexed in Pubmed: 20571255.

18. Timmerman E, Clur SA, Pajkrt E, et al. First-trimester measurement of the ductus venosus pulsatility index and the prediction of congenital heart defects. Ultrasound Obstet Gynecol. 2010; 36(6): 668-675, doi: 10.1002/uog.7742, indexed in Pubmed: 20617506.

19. Timmerman $E$, Oude Rengerink K, Pajkrt E, et al. Ductus venosus pulsatility index measurement reduces the false-positive rate in first-trimester screening. Ultrasound Obstet Gynecol. 2010; 36(6): 661-667, doi: 10.1002/uog.7706, indexed in Pubmed: 20521242.

20. Wagner P, Sonek J, Klein J, et al. First-trimester ultrasound screening for trisomy 21 based on maternal age, fetal nuchal translucency, and different methods of ductus venosus assessment. Prenat Diagn. 2017; 37(7): 680-685, doi: 10.1002/pd.5065, indexed in Pubmed: 28493464.

21. Abele $\mathrm{H}$, Wagner $\mathrm{P}$, Sonek J, et al. First trimester ultrasound screening for Down syndrome based on maternal age, fetal nuchal translucency and different combinations of the additional markers nasal bone, tricuspid and ductus venosus flow. Prenat Diagn. 2015; 35(12): 1182-1186, doi: 10.1002/pd.4664, indexed in Pubmed: 26223508. 